\title{
$\begin{array}{lll}\text { SUGM } & \text { Public Health } \\ \text { Symposium }\end{array}$ Yogyakarta, 7-9 May 2018
}

\section{Minuman Beralkohol dan Kesehatan Masyarakat}

Wildan Akbar

Latar Belakang :

Menurut WHO secara global penggunaan alkohol yang berakibat buruk menyebabkan kurang lebih 3.3 juta kematian per tahunnya yang berhubungan dengan konsumsi minuman beralkohol. Kebiasaan mengkonsusmsi minuman beralkohol merupakan tantangan bagi kesehatan berkepanjangan dapat menimbulkan berbagai masalah yang terkait dengen keshatan. Masalah alkohol semakin meningat selama beberap thun terakhir di Indonesia kemajuan substasial terjadi dalam pemahan kita, tentang masola minum berakohol sebagai ancem teris terus mong terus ne tugas dan mena kese do

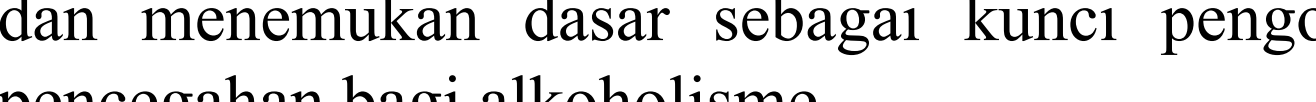
pencegahan bagi alkoholism

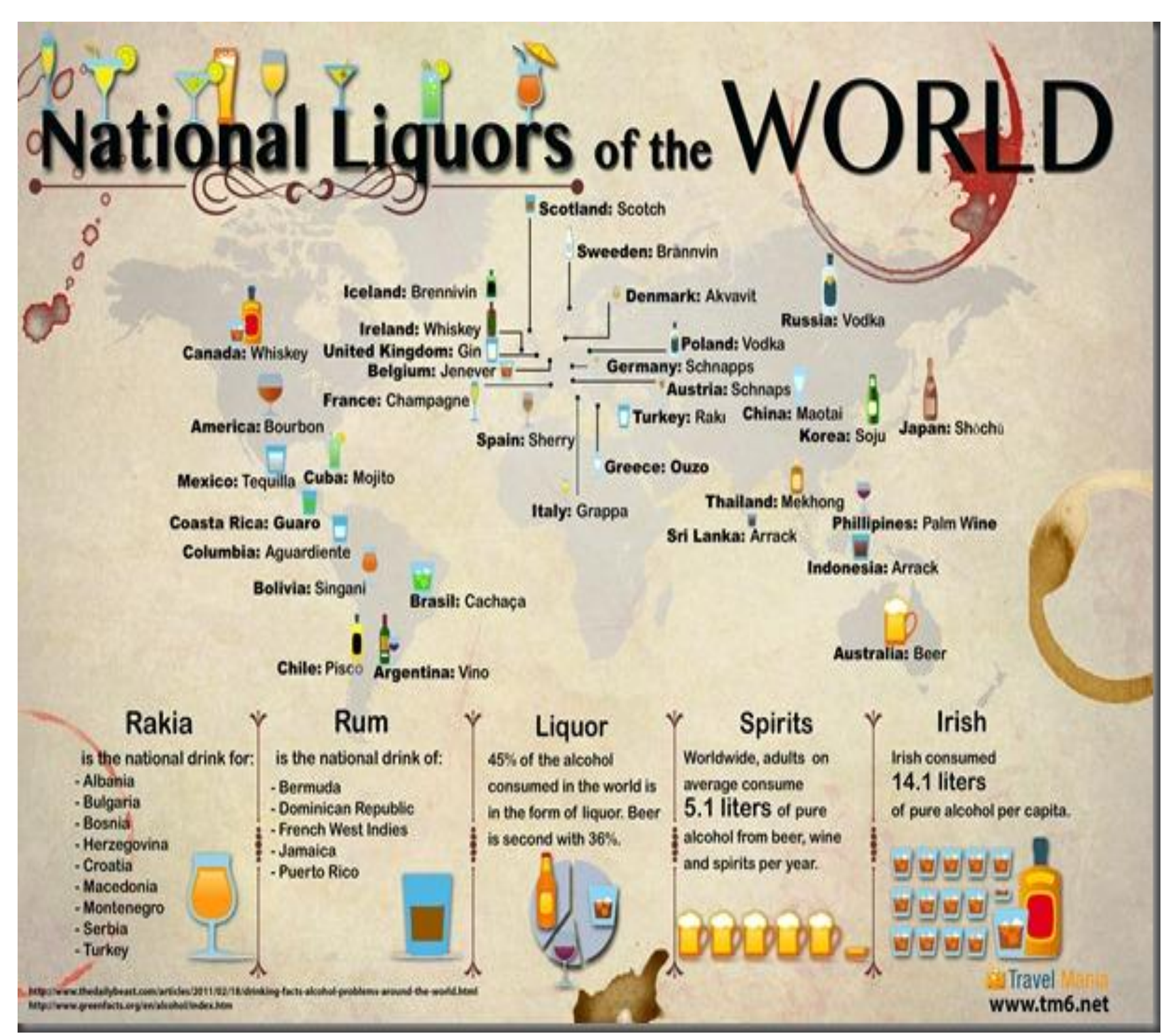

OPLOSAN.

PENGANTAR KEMATIAN

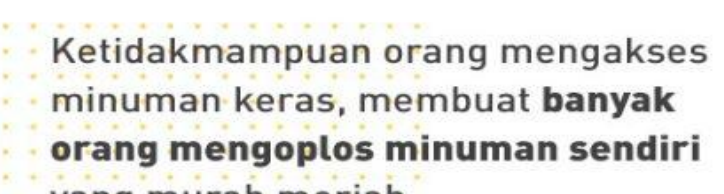

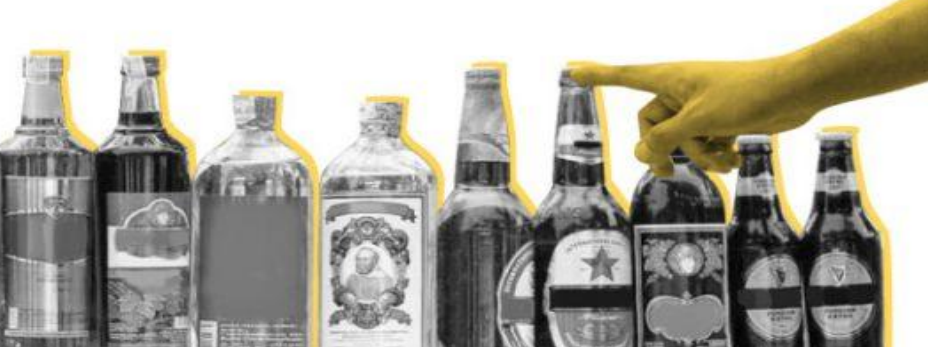

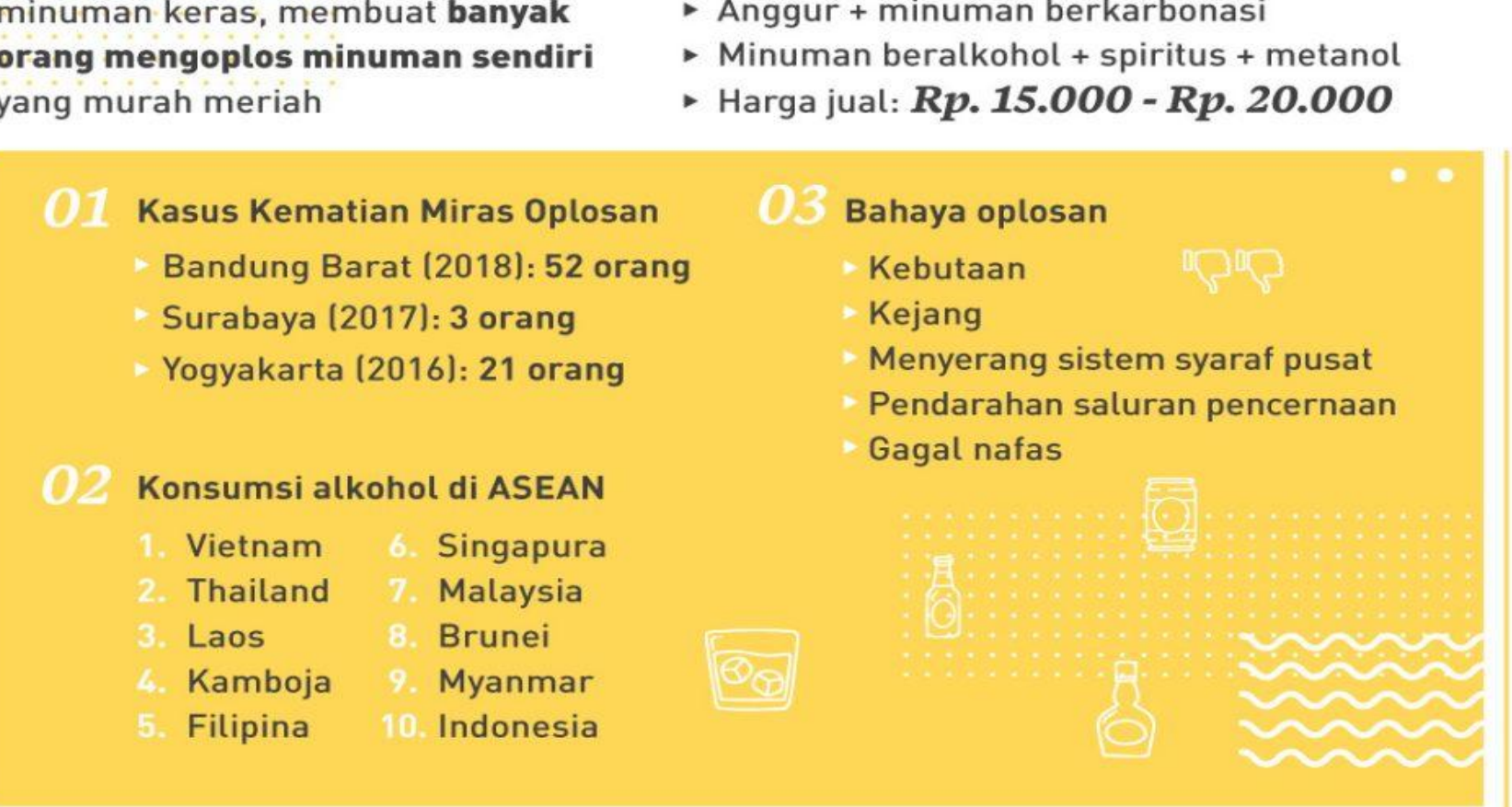

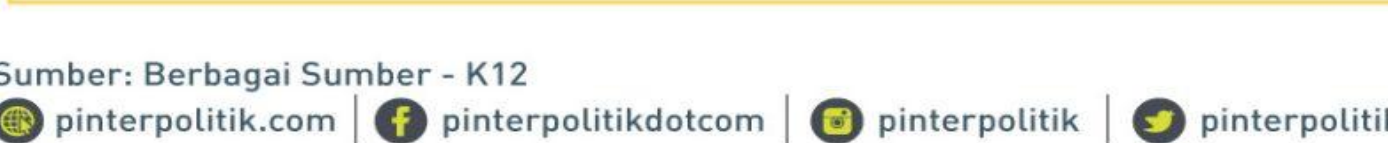
Metode :

Metode penelitian ini merupakan penelitian studi kasus, penelitian ini terletak pada fenomena masa kini atau dinamika yang sedang berlangsung dalam suatu setting tertentu dengan konteks kehidupan nyata.

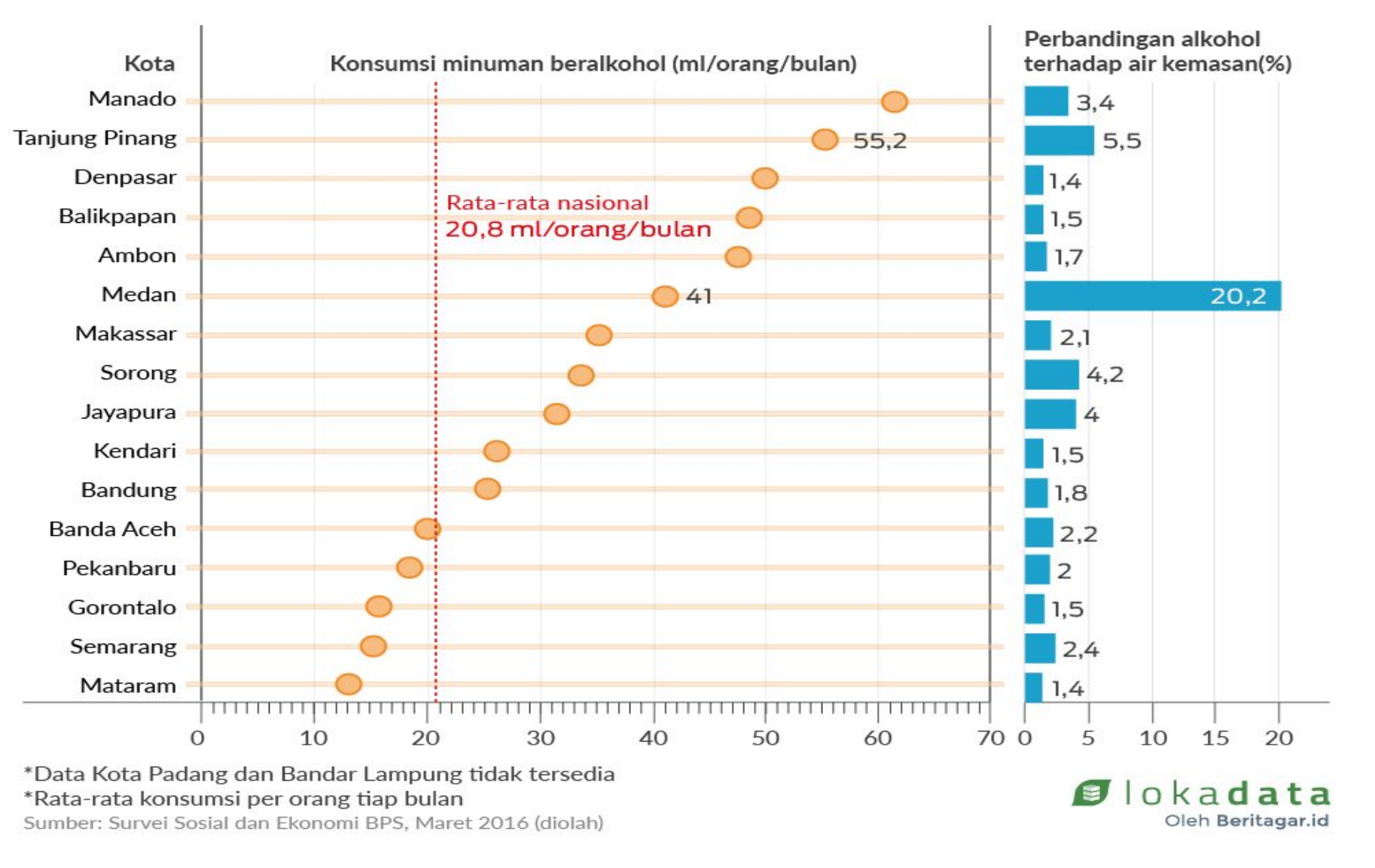

Hasil :

Kegiatan yang dilakukan oleh pihak terkait baik Pemerintah dan instansi terkait seperti preventif dan promotif yang dilakukan untuk mencegah dampak negatif yang $\mathrm{d}$ akibatkan oleh mengkonsumsi minuman beralkohol antar lain dengan sosialisasi, pemajangan spanduk atau pamflet yang berisi ajakan untuk tidak mengkonsumsi minuman beralkohol atau kegiatan yang bersifat pencegahan lainnya Namun hal ini tidak terlalu berdampak kepada masyaraka untuk tidak lagi mengkonsumsi minuman beralkohol perlunya identifikasi pesan tambahan yang mungkin lebih bermafaat bagi masyarakat. Serta tidak ada ketegasan dari Pemerintah daerah atau instansi terkait dalam pengendalian peredaran minuman beralkohol.

Sikap pemerintah masih sebatas melakukan pengawasan dan pengendalian pada minuman beralkohol, belum sampai tahap larangan. Apakah melarang akan lebih baik daripada sekadar pembatasan

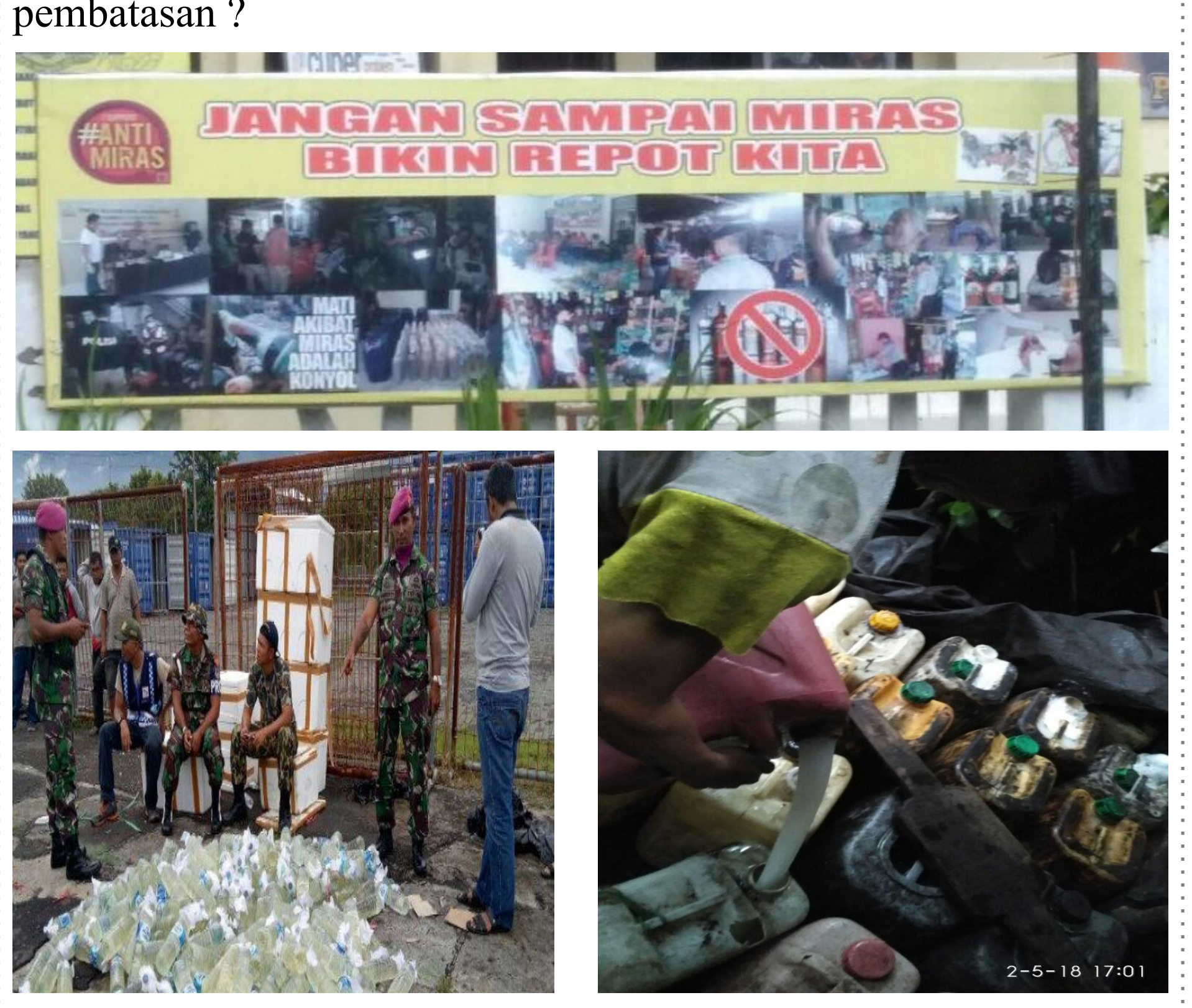

\section{Kesimpulan :}

Pembuatan larangan komprehensif pada berbagai jenis media (misalnya, televisi, radio, papan reklame) serta media sosial seperti facebook dan lainnya bisa menjadi media untuk memberitahukan kepada masyarakat tentang bahayany minuman beralkohol terhadap kesehatan bagi diri sendiri da orang lain. Kemudian hal ini perlu keterlibatan semua pihak untuk melaksanakan pengawasan pada peredaran minuma

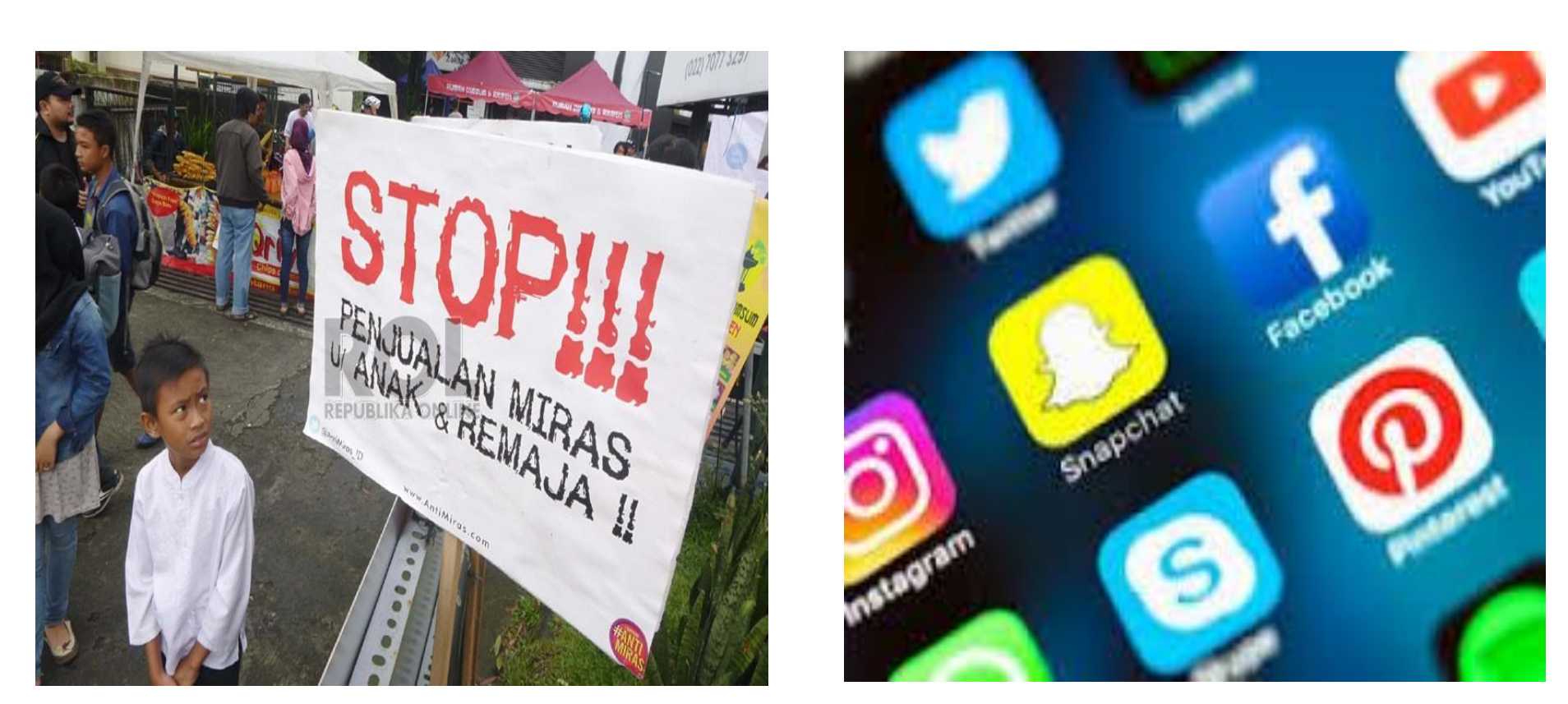

erensi :

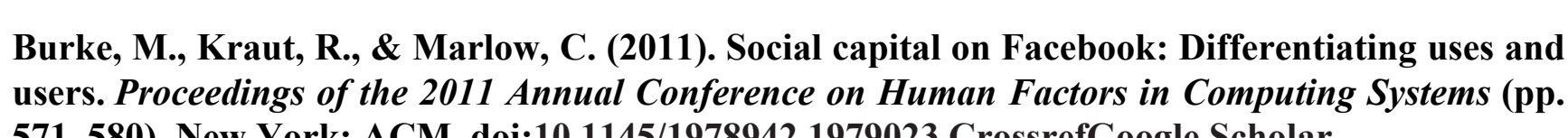
Ferreira-Borges C, Dias S, Babor T, Esser MB, Parry CD. 2015. Alcohol and public health in

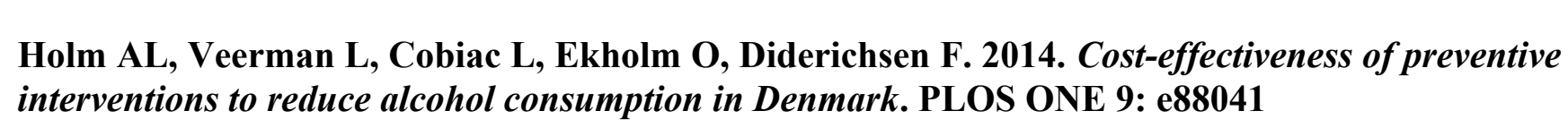

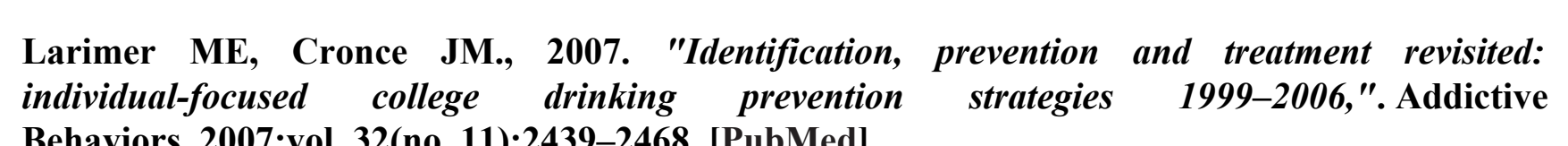

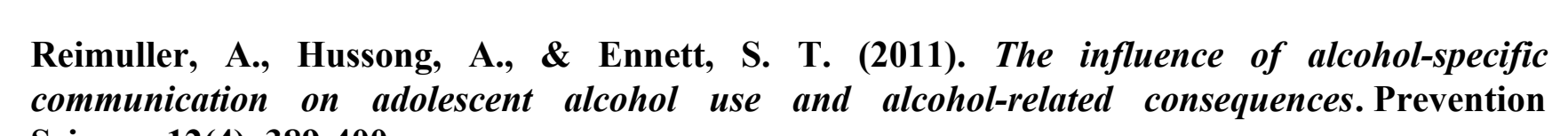
communication on add
Science, $2(24), 389-400$.

Room, R, Babor, T., \& Rehm, J. 2005., Alcohol and public health. The lancet, 365(9458),
519-530." World Health Organization. The Global Status Report on Alcohol and Heathl, 2014. Geneva:
WHO Press 2014. 